\title{
Pengaruh Aspek Sosio-Kultural Masyarakat Loloan terhadap Struktur dan Makna Syair Burdah Melayu di Bali
}

\author{
Riesta Maulidya M1' Fitria Sugiatmi², M. Alan Mabruri ${ }^{3}$ \\ Pendidikan Bahasa dan Sastra Indonesia \\ Universitas Muhammadiyah Malang-1,2,3 \\ Grandhunter736@gmail.com ${ }^{1,2,3}$
}

\begin{abstract}
Abstrak
Syair Burdah Melayu merupakan bentuk tradisi lisan yang saat ini masih terlestari. Syair Burdah Melayu tercipta karena terjadi akulturasi budaya masyarakat pendatang di Loloan, Bali. Perpaduan antara budaya pendatang membentuk absurditas dalam struktur Syair Burdah Melayu. Penelitian ini bertujuan mendeskripsikan makna dan bentuk syair Burdah Melayu Loloan dengan aspek sosio-kultur yang mempengaruhinya. Masalah yang dianalisis adalah makna dan variasi bentuk pada syair Burdah Melayu. Teori yang digunakan adalah teori strukturalisme dinamik oleh Mukarovsky dan Vodicka dikombinasikan dengan teori semiotik oleh Charles Sander Pierce untuk menjelaskan makna dan bentuk syair Burdah Melayu yang dipengaruhi oleh sosio-kultur masyarakat Loloan Barat. Jenis penelitian adalah kualitatif dengan menggunakan kata-kata untuk mendiskripsikan hasil analisis puisi. Dari hasil analisis diketahui bahwa bentuk Syair Burdah Melayu dipengaruhi oleh unsur budaya lain seperti Arab, Jawa, dan Melayu sehingga bentuk Syair ini seolah terpisah tapi sebenarnya satu kesatuan utuh.
\end{abstract}

Kata Kunci: syair; struktural; semiotika; sosio-kultur

\begin{abstract}
Syair Burdah Melayu is a form of oral tradition that currently sustainable. Syair Burdah Melayu was created because immigrant community culture acculturation occur in Loloan, Bali. The fusion of the immigrant culture forming the absurdity in syair Burdah Melayu structure. This study aims to describe the meaning and form of syair Burdah Melayu with socio-cultural impact. Problem analysis are the meaning and variance form in syair Burdah Melayu. Theory used are dynamic structuralism by Mukarovsky and Felik Vodicka combined with semiotic theory by Charles Sander Pierce to explain the meaning and form of syair Burda Melayu that influence by socio-culture of Loloan Barat community. The research method uses qualitative types by using words to describe poetry analysis results. From the results of the analysis it's known that the form of Syair Burdah Melayu is influenced by other cultural elements such as Arab, Javanese, and Malay so the form of the Syair like separate but actually a whole unit.
\end{abstract}

Keywords: poetry; structural; semiotic; socio-culture

\section{Pendahuluan}

Penduduk Loloan saat ini juga didominasi oleh masyarakat etnis Melayu dan Bugis. Menurut Suryawati (dalam Utami dan Kohdrata, 2016: 41) selain penduduk asli Bali, masyarakat Loloan mayoritas pendatang dari etnis Melayu, Bugis, Cina, dan Arab. Adanya etnis Melayu dan Bugis secara tidak langsung membawa kebiasaan bertutur dengan berbahasa Melayu di Loloan. Bahasa Melayu menjadi bahasa utama yang digunakan di Loloan.

Masyarakat pendatang di Loloan menggunakan bahasa Melayu untuk berkomunikasi sedangkan penduduk asli Bali tetap 
menggunakan bahasa Bali. Bahasa Melayu di Bali tidak banyak digunakan. Bahasa ini tergolong sebagai bahasa minoritas. Bahasa Melayu Loloan dianggap sebagai identitas etnis dan lambang komunitas Islam di Loloan (P. Putu M, dkk, 2015: 27). Selain itu pengaruh Islam terlihat dari penggunaan aksara Arab untuk menulis syair Melayu. Maka dari itu kebanyakan tradisi lisan di Loloan tidak menggunakan bahasa Bali, akan tetapi menggunakan bahasa Melayu dengan aksara Arab.

Syair Burdah digunakan sebagai pujian kepada Nabi Muhammad S.A.W dan nasehat untuk berbuat kebajikan. Syair Burdah pada umunya dilantunkan menggunakan bahasa Arab yang berisi berbagai kisah ataupun sanjungan untuk Nabi Muhammad S.A.W. Munculnya Syair Burdah tidak dapat dilepaskan dari pengaruh sastra Arab. Otoktoni menjadi faktor sastra Arab berpengaruh pada sastra MelayuIndonesia sehingga menghasilkan Kasidah Burdah, Kasidah Barzanjy, Kasidah Diba'iy (Mansyur, 2011: 111). Otoktoni ini berperan sebagai paralelisme antar budaya. Paralelisme ini menyebabkan kebanyakan sastra Melayu terpengaruh oleh estetika sastra Arab Islam, pandangan hidup, dan sistem nilai.

Ciri khas yang melekat pada Syair Burdah Melayu Loloan karena dipengaruhi oleh bentuk sastra Melayu, Arab, dan Jawa. Keunikan Syair Burdah Melayu terdapat pada bagian struktur yang dikombinasikan dengan pantun dan ditulis menggunakan akasa Arab. Aksara Arab dalam syair Burdah Melayu tetap dibaca sesuai bahasa melayu. Aksara Arab ini dalam bahasa Jawa disebut dengan Arab Pegon. Arab Pegon adalah tulisan Arab yang bunyinya mengikuti sistem bunyi bahasa jawa (Pudjiastuti, 2009: 273). Pembacaan syair ini disesuaikan dengan irama dari musik tradisional Bali.

Kombinasi bentuk dalam Syair Loloan sangat unik. Sebenarnya kombinasi antara pantun dan syair telah ada pada zaman Melayu klasik. Syairsyair seperti Ken Tambuban juga pernah disisipi oleh Pantun (Fang, 2011, 556). Pada awal mulanya pantun dinyanyikan. Nyanyian dalam Syair dan pantun memiliki kecocokan yang kemudian diiringi Burdah. Selain itu bentuk syair Burdah Melayu ditulis dengan aksara Arab Pegon yang menyebabkan pembaca sulit mengartikan maksud dari syair tersebut. Perpaduan bentuk antara syair yang ditulis dengan Arab Pegon dan pantun saat ini jarang ditemukan. Dengan demikian, kemungkinan akan terjadi kebingungan saat seseorang ingin memahami syair Burdah Loloan. Keunikan pada syair Burdah Loloan ini dapat dipahami berbeda oleh pendengarnya. Berdasarkan latar belakang tersebut maka rumusan masalah dalam tulisan ini yaitu (1) bagaimana relasi sosio-kultur terhadap bentuk syair Melayu Loloan, Bali, (2) Apa makna syair Melayu, Loloan, Bali?

Syair Burdah Melayu Loloan, Bali sangat penting untuk diteliti. Hal tersebut dikarenakan syair Burdah Melayu memiliki keunikan melalui perpaduan bentuk syair dan pantun yang tidak banyak diketahui masyarakat. Tulisan ini memberikan informasi penting supaya masyarakat tidak lupa akan khazanah kekayaan budaya Melayu di Indonesia. Masyarakat akan mengetahui bahwa bentuk karya sastra khususnya syair dipengaruhi 
oleh budaya masyarakatnya. Informasiinformasi dalam tulisan ini dapat dimanfaatkan masyarakat untuk menambah pengetahuan dan membuka wawasan terkait struktur karya sastra serta cara mencari pemaknaan yang baik. Pemahaman terhadap makna karya sastra akan membuat pembaca lebih peka terhadap lingkungan sekitarnya.

Teori yang digunakan dalam penelitian ini adalah teori strukturalisme dinamik oleh Mukarovsky dan Felik Vodicka serta teori semiotik oleh Charles Sander Pierce. Teori struktural dinamik memperhatikan konsep dasar struktualisme yang telah dikaitkan pada hakikat objek (Ratna, 2013:95). Berbeda dengan struktualisme, semiotik memusatkan perhatian pada makna teks. Semiotika merupakan studi tentang penafsiran atau interpretani tanda dalam karya sastra (Ratmanto, 2004:31). Tanda dan petanda harus saling terkait sehingga memunculkan suatu makna.

\section{Kajian Pustaka}

Struktualisme dinamik lahir karena ketidakpuasan atas teori struktualisme yang terpaku terhadap objek tanpa melibatkan aspek luar. Struktualisme Dinamik telah mengaitkan aspek struktur dengan hakikat objek yang selalu mengalami perubahan. Salah satu ahli dalam struktualisme dinamik adalah Mukarovsky dan Felik Vodicka yang berpendapat bahwa karya sastra merupakan proses komunikasi, fakta semiotik, struktur dan nilai-nilai (Ratna, 2011: 93). Proses komunikasi berkaitan dengan aspek sosial di masyarakat. Keterkaitan antara fungsi estetika dan aspek sosial memiliki sifat yang dinamik, variabel, dan tidak tetap. Pendapat Mukarovsky didukung oleh Felik Vodicka yang berpendapat bahwa ilmu sastra memiliki hubungan langsung terhadap konteks sosial budaya namun tidak bersifat searah (Teew, 2012:148). Dengan demikian, maka struktur intrinsik tetap menjadi fokus utama yang memiliki hubungan timbal balik dengan aspek sosio-kultur masyarakat.

Teori lain yang digunakan dalam mengkaji syair ini adalah teori semiotika Pierce. Pierce (dalam Ratna, 2013: 101) menyebutkan ada tiga konsep triadik yaitu (1) sintaksis semiotika; intensitas hubungan tanda dan tanda (2) semantik semiotika; fokus terhadap tanda dan acuannya, (3) pragmatik semiotika; hubungan antara pengirim dan penerima. Tanda-tanda dalam teori Pierce dihubungkan satu sama lain sehingga menimbulkan makna yang dimaksudkan. Tanda diinterpretasikan sesuai acuan yang dihubungkan dengan sosiokultur di masyarakat.

Struktualisme dinamik digunakan karena bentuk Syair Burdah Melayu dipengaruhi oleh aspek luar berupa budaya dan filosofis religiusitas masyarakat Loloan. Teori ini memudahkan dalam menganalisa bentuk syair Loloan yang berbeda dari syair lainnya. Teori Semiotika bertujuan mengenali makna syair Burdah Melayu Loloan berdasarkan tanda-tanda yang menyertainya.

\section{Metode Penelitian}

Jenis penelitian yang digunakan yaitu kualitatif dengan pendekatan sosiologi sastra. Penelitian kualitatif merupakan cara untuk menafsirkan dan menyajikan data dalam bentuk deskriptif (Ratna, 
2013: 46). Data-data yang telah ada kemudian ditafsirkan supaya pembaca paham maksud isi karya sastra. Pendekatan sosiologi sastra yang berfokus pada karya sastra. Dasar filosofis pendekatan sosiologi yaitu adanya hubungan antara karya sastra dan masyarakat (Ratna, 2013 :60). Hubungan antara masyarakat dan karya sastra pada akhirnya saling mempengaruhi sehingga tercipta bentuk karya sastra yang berbeda.

Penelitian ini menggunakan metode deskriptif analitik. Metode deskripsi analisis bisa didapatkan dari penggabungan dua metode yang saling mendukung (Ratna, 2013: 53). Kedua metode tersebut bertujuan untuk menguraikan informasi mendetail mengenai aspek-aspek pembentuk karya sastra dan menghubungkannya menjadi satu kesatuan yang memunculkan makna.

Sumber data yang digunakan ialah catatan syair Burda Melayu Loloan untuk memudahkan peneliti mendeskripsikan bentuk syair Burdah Melayu Loloan di Bali. Data yang digunakan berasal dari bait-bait syair Burda Melayu Loloan. Data lain yang dibutuhkan yaitu informasi terkait kondisi geografis, kondisi budaya masyarakat, tepatnya di daerah Loloan, Bali.

Instrumen yang digunakan yaitu peneliti, wawancara narasumber bapak Said Zen dan Sayid Usman Al-Qodri selaku pemilik Burdah Mujahidin Loloan di Bali. Panduan teknik pengumpulan data yang digunakan dalam penelitian ini adalah teknik dokumentasi yang dilakukan secara langsung melalui kamera, perekaman dilakukan dengan menggunakan alat perekam, pengamatan dilakukan selama dua hari di Desa Loloan Barat, Bali, selanjutnya pencatatan dilakukan ketika wawancara di buku tulis, dan wawancara dilakukan dengan menanyakan masalah terkait.

Teknik analisis data yang digunakan model analisis isi. Model analisis isi menekankan pemaknaan isi komunikasi dan isi interaksi simbolik yang terjadi pada peristiwa komunikasi (Ratna,2013 :49). Teknik ini dilakukan dengan mengumpulkan data mentah, mengolah data, membaca data berupa catatan Syair Burdah Melayu Loloan di Bali kemudian mendiskripsikan masalah yang terjadi pada bentuk Syair Burdah Melayu Loloan lalu dihubungkan dengan aspek sosial-kultural masyarakat Loloan di Bali.

\section{Relasi Bentuk Syair Burdah Melayu Loloan} dengan Unsur Sosio-kultural Masyarakat Loloan

Struktur syair Burda Melayu Loloan terdiri dari aksara Arab pegon, pantun tradisional melayu, dan syair bahasa arab yang langsung diterjemahkan oleh pemilik burdah. Runtutan dalam syair Burdah Melayu dapat dilihat dari gambar di bawah. Pertama syair berbentuk pegon dibacakan, kemudian disisipi pantun nasehat, dan ketiga ada tambahan syair bahasa arab. Semua syair dinyanyikan oleh pembaca syair secara khitmad.

\section{Teks Syair Burdah Melayu Loloan, Bali}


Poetika : Jurnal Ilmu Sastra

Vol. VI No. 1 Juli 2018
DOI $10.22146 /$ poetika.35713

ISSN 2338-5383 (print) ; 2503-4642 (online)

\begin{tabular}{|c|c|}
\hline & 0 \\
\hline & $\begin{array}{l}\text { nilah yang Bernama Syair Citra Kubur Ba- } \\
\text { naru }\end{array}$ \\
\hline & $\begin{array}{l}\text { Kisah mula disebutkan, suatu pasal kita nya- } \\
\text { akan, } \\
\text { ekedar ingin maka disyairkan, menjadi sun- } \\
\text { aah semua yang mendengar }\end{array}$ \\
\hline & $\begin{array}{l}\text { Hendaklah ingat wahai akhwani, janganlah } \\
\text { upa di dunia ini } \\
\text { uka bermain ke sana sini, hidup kita akanlah } \\
\text { ani }\end{array}$ \\
\hline & $\begin{array}{l}\text { anganlah riya' janganlah takkabur, pandang } \\
\text { lehmu kepada kubur, } \\
\text { i sanalah tempat tubuh nan lebur, han- } \\
\text { urlah luluh seperti bubur }\end{array}$ \\
\hline & $\begin{array}{l}\text { ewaktu badan sehat sentosa, kerjakan iba- } \\
\text { lah senantiasa, } \\
\text { ikalau sudah letih dan lesu, berbagi bagi sa- } \\
\text { it deras }\end{array}$ \\
\hline & $\begin{array}{l}\text { Cakkala kita hampirlah mati, datang penyakit } \\
\text { idak berhenti, } \\
\text { ahabat hendaknya datang mengobati, } \\
\text { isahakan baik tanpa menyakiti }\end{array}$ \\
\hline
\end{tabular}

\begin{tabular}{|c|}
\hline Aksara Arab (Pegon) \\
\hline انيله يُّبر نا م شتير جتر اذالم قبو رما جم يهار \\
\hline 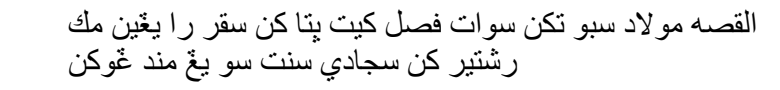 \\
\hline 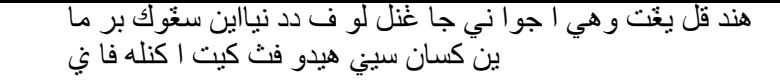 \\
\hline 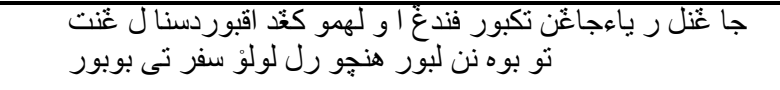 \\
\hline 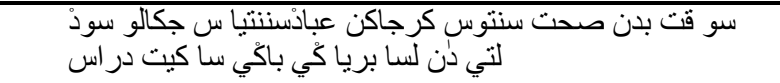 \\
\hline 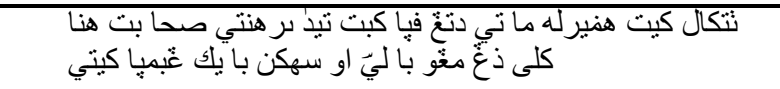 \\
\hline
\end{tabular}

\begin{tabular}{|l|}
\hline Pantun Nasehat yang disisipkan \\
\hline Janganlah kita 3x merasa sedih \\
Walaupun hidup dalam tiada 2x \\
Kuatkan hati 3x jangan merintih \\
Adakala kita kuat dalam ibadah $2 \mathrm{x}$ \\
\\
Kuatkanlah hidup 2x dalam kemiskinan \\
Janganlah merasa rendah diri 2x \\
Walaupun kita 3x dipandang miskin. \\
Asalkan kita kaya hati 2x \\
\hline
\end{tabular}

Sudahlah jatuh $3 \mathrm{x}$ tertimpa tangga.

Tangannya patah menjadi tiga $2 \mathrm{x}$

Orangpu tahu $3 \mathrm{x}$ kita tak punya

Janganlah kita membusungkan dada $2 \mathrm{x}$

Apalah guna $3 x$ hidup kita kaya.

Kalaulah tidak pernah sedekah $2 x$

Di dalam dunia $3 x$ hidup bahagia

Di akhirat nanti kita sengsara $2 x$

Marilah kita 3x banyak sedekah

Sedekah itu menambah rizki $2 \mathrm{x}$

Rizki kita 3x tak akan kemana

Asalkan sedekah sepenuh hati

\begin{tabular}{|l|}
\hline \multicolumn{1}{|c|}{ Bahasa Melayu } \\
\hline Bagai bunga indah jelita \\
Bagai purnama tinggi mulia \\
Bagai samudra murah melimpa \\
Bagai masa berputar segera \\
\hline Hari Maulid Rasul Allah \\
Menunjukkan kemanusiaan cikal bakal \\
Alangkah megahnya permulaannya \\
Alangkah indahnya kesudahannya \\
\hline
\end{tabular}

\begin{tabular}{|c|}
\hline Bahasa Arab \\
\hline 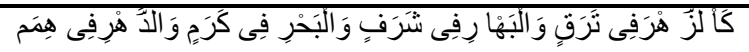 \\
\hline 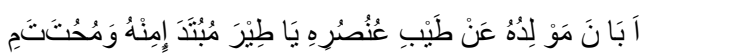 \\
\hline
\end{tabular}

Kondisi sosio-kultural di masyarakat selalu mempengaruhi bentuk budaya yang dihasilkan. Pengaruh budaya jawa terlihat dari penggunaan pegon dalam penulisan syair Burdah. Kompleksitas akulturasi budaya terlihat mempengaruhi betuk syair burdah melayu. Tulisan aksara arab pegon terpengaruh dari budaya jawa, bentuk syair a-a-a-a dengan kombinasi pantun terpengaruh budaya melayu, isi dalam syair tersebut terpengaruh oleh sastra arab. Puisi Arab lazimnya terbagi dua dengan pembagian mentrum yang sama (Manshur, 2011: 6). Pembacaan syair Burdah Melayu disesuaikan dengan nada bahasa Bali yang lembut 
dan mendayu.

Narasumber yaitu bapak Zen selaku anak pemilik burdah Loloan menyatakan bahwa syair burdah melayu Loloan ini memiliki keunikan yang berbeda dengan syair burdah lainnya. Syair burdah melayu ini dikombinasikan dengan pantun - pantun nasihat dengan mengunakan bahasa melayu khas Loloan. Pembacaan syair tersebut diiringi dengan permainan alat musik. Alat musik yang mengiringi syair ini disebut dengan burdah. Permainan burdah terdiri dari 13 sampai 15 pemain yang mayoritas terdiri dari laki laki yang berusia diatas 50 tahun.

Pembacaan syair burdah melayu ini merupakan sebuah kegiatan yang sakral dan dilakukan hanya pada waktu - waktu tertentu. Islam menjadi inspirasi dalam memanfaatkan segala sarana dan prasarana untuk sosialisasi ajaran islam (Karim, 2016: 24). Sosialisasi ajaran islam terbukti sukses dengan respon yang diberikan masyarakat. Respon masyarakat Loloan terhadap syair burdah melayu ini sangatlah positif. Pembacaan syair burdah melayu selalu dinanti - nantikan dalam banyak acara langsung yang diselengarakan di daerah Loloan.

Syair burda melayu dalam upacara adat masyarakat Loloan masih dilestarikan sampai saat ini. Masyarakat Loloan menggunakannya sebagai pengiring doa. Syair ini utamanya digunakan saat acara syukuran umat beragama islam di Loloan. Syair Burda Melayu menjadi bagian yang tidak dapat dilepaskan dari upacara adat setempat. Secara spesifik syair Burda Melayu digunakan dalam upacara syukuran tujuh bulan, Maulid Nabi, dan ruahan (acara sebelum bu- lan ramadhan), potong rambut bayi. Syair Melayu yang bernuansa islam berfungsi untuk penyiaran agama, ungkapan rasa syukur kepada Allah, dan pujian kepada Nabi Muhammad. Meskipun bernuansa islami, syair Melayu di Loloan tetap memiliki ciri irama khas Bali.

Bentuk atau tipografi pada syair Burdah Melayu Loloan adalah lurus, bait pertama sampai kelima lebih panjang secara vertikal tapi lebih pendek secara horizontal dan memiliki bentuk seperti puisi multilingual. Puisi multilingual menggunakan berbagai bahasa dalam penyampaian maksudnya. Perbedaanya puisi multilingual biasanya adalah puisi konteporer, hal tersebut berbeda dengan syair Burdah Melayu yang memiliki maksud penyampaian yang jelas. Selain itu bentuk Syair Burdah Melayu unik karena menggabungkan bentuk puisi sastra arab yang memiliki dua penggalan, pantun Melayu terdiri dari empat baris satu bait, dan multilingual antara bahasa Arab, aksara Arab Pegon dan Melayu.

Diksi berkaitan dengan pemilihan kata yang tepat. Pilihan kata dalam syair ini adalah kata-kata Melayu tradisional. Sastra Melayu memiliki selalu mengaitkan satu kata dengan kata yang lain supaya menimbulkan makna yang padu. Ophuisjsen (dalam Fang, 2011: 557) mengungkapkan adanya hubungan antara pasangan I dan II dalam penulisan pantun. Maka dari itu pilihan kata pada puisi ini sama sekali tidak sederhana dan rumit. Hal tersebut ditunjukkan bait kesembilan dalam syair Burdah:

Apalah guna $3 \mathrm{x}$ hidup kita kaya. Kalaulah tidak pernah sedekah $2 x$

Di dalam dunia $3 x$ hidup bahagia 
Di akhirat nanti kita sengsara $2 \mathrm{x}$

Pasangan I dan pasangan II memiliki keterkaitan dalam hal tiadanya manfaat dari sesuatu yang dimiliki seseorang jika tidak digunakan dengan baik. Pada baris pertama dijelaskan kepemilikan harta tidak berguna jika hanya dimiliki sendiri tanpa disedekahkan. Hal tersebut memiliki korelasi dengan pasangan II yaitu hidup bahagia tidak ada manfaatnya jika hidup di akhirat sengsara. Diksi memudahkan pembaca dan pendengar mencerna isi dalam teks puisi.

Perasaan yang dilukiskan saat mendengar syair Burdah Melayu adalah perasaan haru dan cinta kasih karena adanya pengingat akan kematian, Tuhan, dan Rasul. Perasaan melibatkan emosi yang timbul dari dalam diri pembaca. Syair Burdah Melayu dibuka pertama kali menggunakan awalan mengenai peringatan tentang ajakan berbuat kebaikan. Perasaan mengenai berbuat baik diungkapkan melalui bait kelima dan keenam yaitu:

Takkala kita hampirlah mati, datang penyakit tidak berhenti, sahabat hendaknya datang mengobati, usahakan baik tanpa menyakiti

Janganah kita $3 x$ merasa sedih Walaupun hidup dalam tiada $2 \mathrm{x}$ Kuatkan hati 3x jangan merintih Adakala kita kuat dalam ibadah 2x

Kedua bait pada puisi tersebut menunjukkan adanya perasaan kesedihan meski tidak ada niatan untuk menyakiti. Kematian selalu identik dengan rasa sedih maka dari itu kedua bait tersebut menggunakan kata sedih untuk mengungkap- kan keresahan hati. Keresahan hati pada Syair Burdah Melayu diobati dengan kata-kata penyemanngat dibait-bait selanjutnya. Adapun perasaan cinta kasih ditunjukkan pada syair bait kesebelas yaitu:

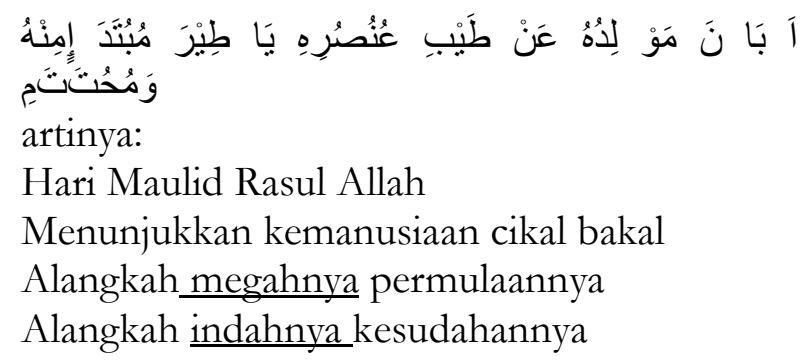

Kata megah dan indah menunjukkan adanya kesenangan di dunia. Perasaan bahagia karena Maulid Nabi akan segera tiba diungkapkan oleh penyair melalui baris ketiga dan keempat. Bait keempat dan ketiga meunjukkan harapan positif tentang perayaan Maulid Nabi. Perasaan yang dituangkan dalam bait syair akan berimplikasi terhadap bentuk nada yang digunakan.

Nada yang digunakan dalam syair Burdah Melayu ini adalah nada tenang, tidak tinggi tapi bergelombang. Menyesuaikan dengan nada khas Bali. Nada lirih mengikuti kesan yang ada pada setiap bait syair. Nada rendah, halus, dan mendayu menjadi ciri nada syair Burdah Melayu Loloan. Bait kedua dibawah dilantunkan dengan tenang dan mendayu.

Hendaklah ingat wahai akhwani, janganlah lupa di dunia ini

suka bermain ke sana sini, hidup kita akanlah fani

Kata wahai Akhwani diugkapkan sebagai seruan yang halus kepada pendengar. Sebagai lanjutan dari seruan tersebut ke sana sini juga diucapkan 
dengan halus untuk menyelaraskan bunyi pada syair. Nada yang halus bertujuan supaya pendengar merasa tenang saat mendengarkan.

Rima yang dibawakan adalah rima terbuka yang menandakan bahwa persamaan bunyi yang terdapat suku akhir terbuka atau dengan vokal yang sama dan baitnya dibagi menjadi dua yaitu a-a. Akan tetapi karena disisipi pantun rima kedua berbentuk a-b-a-b. Setelah itu berbentuk bahasa arab yang terjemahannya berbentuk a-a-a -a kembali. Penggalan bait-bait awal syair yang mencerminkan perbedaan akhiran pada rima:

\section{Bait kelima: \\ Takkala kita hampirlah mati, datang pen- yakit tidak berhenti, \\ sahabat hendaknya datang mengobati, usahakan baik tanpa menyakiti}

Bait pertama pada pantun Nasehat dan keenam dalam urutan syair Burdah Melayu:

Janganah kita $\underline{\underline{3}}$ merasa sedih

Walaupun hidup dalam tiada $\underline{2 \boldsymbol{x}}$

Kuatkan hati $\underline{\mathbf{3 x}}$ jangan merintih

Adakala kita kuat dalam ibadah $\underline{\underline{2}}$

Bait pertama pada puisi arab dan bait kesebelas pada syair Burdah Melayu

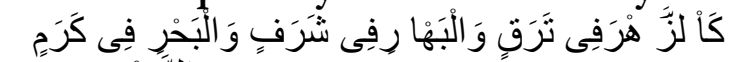

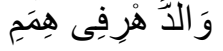

artinya:

Bagai bunga indah jelita

Bagai purnama tinggi mulia

Bagai samudra murah melimpa

Bagai masa berputar segera

Pada syair Burdah Melayu Loloan terdapat tiga jenis akhiran rima yang membentuk kesatuan utuh yaitu a-a, a-b-a-b, dan a-a-a-a. Lazimnya sebuah syair biasanya hanya diikuti oleh bunyi akhiran yang sama. Bunyi syair Burdah Melayu berbeda karena ada unsur percampuran sastra
Arab, Melayu, Jawa di dalamnya. Keseluruhan akhiran bunyi ini secara sistematis akan menentukan sumbang tidaknya sebuah syair.

Ritme yang ada dalam syair Burdah Melayu juga dapat dilihat dari bait kelima, keenam, dan kesebelas. Ritme muncul karena pengulangan bunyi yang dihasilkan oleh syair. Ritme berhubungan dengan nada. Ritme dapat menjadi kuat lembutnya suatu suara dibunyikan. Pada tiga bait yang dicontohkan ritme berubah, tidak sama karena menyampaikan tiga hal berbeda dengan pengulangan bunyi yang berbeda pula. Metrum terjadi saat ada penekanan dalam pengulangan pada bait puisi. Metrum yang ada pada syair Burdah Melayu terjadi pada bait keenam syair yang berupa pantun. Terjadi pengulangan pada pantun di syair Burdah Melayu karena pantun tidak hanya dibacakan tapi juga dinyayikan.

Pencitraan dalam puisi dibagi berdasarkan beberapa jenis. Imaji terbagi atas imaji suara, imai visual, dan imaji taktil (Muntazir, 2017: 213). Imaji membuat pembaca atau pendengar seolah-olah melihat dan dapat merasakan secara indrawi. Pencitraan yang terdapat pada syair Burdah Melayu Loloan di antaranya:

Imaji Visual: pada bait ketiga baris pertama mencerminkan pengimajian terhadap penglihatan, seolah-olah pembaca diajak melihat dalam kubur.

Janganlah riya' janganlah takkabur, pandang olehmu kepada kubur,

Di sanalah tempat tubuh nan lebur, hancurlah luluh seperti bubur

Imaji auditif: Pembaca seolah-olah dapat mendengar seseorang merintih saat pengungkapan syair Burdah Melayu pada bait keenam.

Janganah kita 3x merasa sedih 
Walaupun hidup dalam tiada $2 \mathrm{x}$

Kuatkan hati $3 x$ jangan merintih

Adakala kita kuat dalam ibadah $2 x$

Imaji Taktil: pembaca seolah-olah merasakan setuhan saat mendengar syair Burdah Melayu. Hal tersebut diungkap dalam bait kedelapan.

Sudahlah jatuh 3x tertimpa tangga.

Tangannya patah menjadi tiga $2 \mathrm{x}$

Orangpu tahu $3 x$ kita tak punya

Janganlah kita membusungkan dada $2 \mathrm{x}$

Kata konkret berkaitan dengan proses pengimajian. Kata konkret memunculkan imajinasi yang dapat ditangkap oleh indra (Muntazir, 2017: 213). Kata konkret dalam syair Burdah Melayu di antaranya pada bait-bait yang telah tersusun secara keseluruhan membentuk kata konkrit. Sambungan Kata-kata konkrit tersebut akhirnya membentuk pencitraan sehingga dapat diproyeksikan dalam pikiran setiap pendengar dan pembaca. Contoh penggalan syir di atas seolah membuat pendengar dan pembaca syair merasakan secara nyata akhir kehidupan yang ditandai dengan kata "kubur". Begitu juga rasa sakit diungkapkan dengan kata "merintih" dan "tangan yang patah". Pencitraan tersebut didasarkan oleh sikap religiusitas masyarakat di Loloan.

\section{Tema}

Tema yang ada dalam syair Burdah Melayu tergolong sebagai tema jasmaniah. Tema jasmaniah menggambarkan keadaan perjalanan tentang kehidupan. Perjalanan akan kehidupan akan terus berlanjut sampai akhirnya meninggal. Tema selalu memiliki keterkaitan secara koherensif dengan unsur lainnya (Endraswara, 2013:
53). Tema pada syair Burdah Melayu selanjutnya ditampilkan dalam wujuh utuh berupa bait-bait yang memuat unsur pokok lainnya. Tema didapatkan setelah membaca keseluruhan syair Burdah Melayu. Pemilihan tema terindikasi mendapat pengaruh dari sastra Arab. Hal tersebut karena tema tentang kematian dan kesenangan dunia juga banyak dibuat oleh penyair Arab (Mansyur, 2013:6). Dengan demikian tema yang terdapat dalam Syair Budah Melayu Loloan secara spesifik adalah pengingat tentang kematian dan Kelahiran Nabi.

\section{Amanat}

Amanat merupakan pesan yang tersirat dalam karya sastra. Pesan dalam syair Burdah Melayu didapatkan setelah membaca keseluruhan isi. Keseluruhan aspek-aspek dalam makna syair Melayu memberikan informasi terkait kehidupan yang sementara dan akibat jika menyianyiakannya. Maka dari itu dapat ditarik kesimpulan bahwa amanat dari syair Burdah Melayu adalah janganlah bersifat sombong, pelit, lupa pada Tuhan karena sesungguhnya manusia akan meninggal dan kembali kepada Tuhan.

\section{Makna Syair Burdah Melayu Loloan}

\section{Tanda sebagai Wujud Gejala Umum}

Tanda sebagai wujud gejala umum dapat terbagi menjadi tiga bagian. Tanda-tanda tersebut di antaranya qualisigns, sinsigns, legisighn( Ratna, 2011:101). Syair Burdah Melayu memiliki representamen di antaranya Legisighn ditunjukkan pada bait pertama

Kisah mula disebutkan, suatu pasal kita nya- 
takan, sekedar ingin maka disyairkan, menjadi $\underline{\text { sunnah semua yang mendengar }}$

kutipan bait di atas menjelaskan mengenai hukum ajaran dalam agama Islam. Jika seseorang mengetahui dan diberitahu arahan tapi ia tetap melakukan suatu keburukan maka ia akan mendapat dosa atau hukuman.

\section{Objek}

Objek adalah segala sesuatu yang menjadi acuan dalam syair Burdah Melayu Loloan. Objek terbagi menjadi tiga yaitu Ikon, Indeks, dan Simbol. Indeks dalam syair Burdah Melayu ditunjukkan oleh bait kesepuluh:

Marilah kita 3x banyak sedekah

Sedekah itu menambah rizki $2 \mathrm{x}$

Pemaknaan dari bait kesepuluh dapat dikatakan menjadi salah satu ajaran Islam. Islam mengajakan jika memberi seseorang, maka akan ada balasan lebih banyak dari Tuhan. Makna tersirat dalam bait ini sebenarnya mengajak pembaca untuk sering memberi orang yang tidak mampu dan mengasihi sesaman umat manusia.

\section{Interpretant}

Interpretant dihubungkan dengan kondisi pendengar atau pembaca. Interpretant terdiri dari rhyme, dicisighn, dan argument. Bentuk dari Rheme dapat terlihat dari kemungkinan konsep sebagai berikut:

\section{Bentuk Pujian Terhadap Rosul}

Menurut narasumber yaitu Bapak Usman
Syair burda melayu banyak digunakan untuk acara keIslaman. Bentuk pujian terhadap baginda besar Nabi Muhammad SAW dilestarikan oleh masyarakat Loloan Bali dalam berbagai bentuk acara besar islam yang terdapat di daerah Loloan. Syair burdah berisikan cerita atau peristiwa perjalanan nabi yang diceritakan menggunakan sebuah syair dan diiringi dengan gebukan alat musik Burdah sebagai bentuk ciri khas dari desa Loloan. (Setiawan 2015:2) keagungan yang diungkapkan dalm syair burdah adalah bentuk apresiasi terhadap sosok Muhammad SAW yang memiliki pengaruh besar terhadap umat manusia karena beliau adalah sebaik-baiknya ciptaan, manusia yang yang berakhlah baik serta berpudi pengerti santun.

\section{Kesimpulan}

Syair Burdah Melayu lahir karena adanya unsur sosio-kultural yang melandasinya. Keseluruhan isi dalam syair Burdah Melayu kebanyakan membahas tentang syariat Islam. Bentuk dari Syair Burdah secara Tipografi dapat dikatakan sebagai bentik campuran karena adanya kaidah penulisan syair Arab, pantun Melayu, serta syair Melayu. Berbagai macam penulisan puisi lama yang digabung menjadi satu membuat syair Burdah Melayu berbeda dari syair Burdah yang lain. Syair Burdah Melayu kental dengan ajaran agama Islam. Makna dalam syair burdah mengajarkan tentang kebajikan dalam hidup. Sebagai tradisi lisan, Burdah Melayu sampai saat ini masih dilestarikan dengan baik. Nilai-nilai luhur masih dipengang oleh masyarakat Loloan, Bali. Bahasa Melayu di Loloan, Bali sangat dijunjung tinggi sehingga diharapkan Syair Burdah Melayu mendatang akan 
Poetika : Jurnal Ilmu Sastra

Vol. VI No. 1 Juli 2018
DOI $10.22146 /$ poetika.35713

ISSN 2338-5383 (print) ; 2503-4642 (online)

tan Struktural. Padang: Sukabina Press.

\section{Daftar Pustaka}

Endraswara.2013. Metodelogi Penelitian Sastra. Yogyakarta. Yogyakarta: CAPS.

Fang, Liaw Yock. 2011. Sejarah Kesusastraan Melayu Klasik. Jakarta: Eirlangga

Karim, M. Abdul. 2016. Toleransi Umat Beragama di Desa Loloan, Jembrana, Bali (Ditinjau dari Perspektif Sejarah), Jurnal Analisis, 16 (1): 1-32.

Mansyur, Fadlil Munawar. 2011. Perkembangan Sastra Arab dan Teori Sastra Islam.Yogyakarta: Pustaka Pelajar.

Muntazir. 2017. Struktur Fisik dan Struktur Batin pada Puisi Tuhan, Aku Cinta Padamu Karya WS Rendra. Jurnal Pesona, 3(2):208223.

P. Putu, Anak Agung, dkk. 2015. Adaptasi Kosakata Bahasa Bali dalam Bahasa Melayu Loloan Bali. Jurnal Litera, 14(1): 26-36.

Pudjiastuti, Titik. 2009. Tulisan Pegon Wujud Identitas Islam-Jawa: Tinjauan atas Bentuk dan Fungsinya. Jurnal Subuf, 2(2): 271-281.

Ratmanto, Teguh. 2004. Pesan: Tinjauan Bahasa, Semiotika, dan Hermeneutika. Jurnal MediaTor, 5(1): 29-37.

Ratna, Nyoman Kutha. 2013. Teori, Metode,dan Teknik Penelitian Sastra. Yogyakarta: Pustaka Pelajar.

Setiawan, Eko. 2015. Nilai-Nilai Religius dalam Syair Shalawat Burdah. Jurnal Lingua,10(1): 1 $-8$.

Teeuw, A. 2012. Sastra dan Ilmu sastra. Jakarta : Dunia Pustaka Jaya.

Utami, Ni Wayan Febriana \& Kodrata, Naniek. 2016. Identifikasi Keunikan Lansekap Kampung Loloan di Jembara. E-Jurnal Arsitektur Lansakep, 2(1): 41-50.

Zaim, M. 2014. Metode Penelitian Babasa: Pendeka- 